\title{
A imagem do negro no humor gráfico brasileiro do século XIX até meados do século XX
}

\author{
NobuYoshi CHINEN \\ Universidade de São Paulo (São Paulo, Brasil)
}

\begin{abstract}
RESUMO: A REPRESENTAÇÃO DE PERSONAGENS NEGROS NAS PUBLICAÇÕES DE HUMOR GRÁFICO NO BRASIL (QUADRINHOS, CARICATURAS ETC.) FORAM MARCADAS PELO USO DE UM CÓDIGO VISUAL EM QUE PREDOMINAVAM OS ESTEREÓTIPOS. O PRESENTE ARTIGO TRAÇA UM RESUMO DESSE PANORAMA, COM POUCOS, PORÉM SIGNIFICATIVOS, EXEMPLOS DESDE MEADOS DO SÉCULO XIX ATÉ O FIM DO SÉCULO XX, E DEMONSTRA QUE AINDA HÁ RESQUÍCIOS DAQUELES CLICHÊS, APESAR DA MUDANÇA SIGNIFICATIVA DE DISCURSO, COM O NEGRO ASSUMINDO O PROTAGONISMO NA NARRATIVA.
\end{abstract}

ABSTRACT: THE USE OF A VISUAL CODE IN WHICH STEREOTYPES PREDOMINATE HAS BEEN PREVALENT IN THE REPRESENTATION OF BLACK CHARACTERS IN BRAZILIAN GRAPHIC HUMOR (COMIC STRIPS, CARTOONS, ETC.). THIS ARTICLE PROVIDES AN OVERVIEW OF THESE PUBLICATIONS, BY WAY OF A FEW KEY EXAMPLES RANGING FROM THE MIDDLE OF THE 19TH CENTURY UNTIL THE END OF THE 20TH. I AIM TO SHOW THAT CERTAIN CLICHÉS REMAIN IN USE, THOUGH BLACK CHARACTERS HAVE COME TO OCCUPY THE MAIN ROLES IN SUCH NARRATIVES, A VERY IMPORTANT SHIFT IN VIEWPOINT.

PALAVRAS-CHAVE: HUMOR GRÁFICO, CHARGE, HISTÓRIAS EM QUADRINHOS, RACISMO, PRECONCEITO.

KEYWORDS: GRAPHIC HUMOR, CARTOON, COMICS, RACISM, PREJUDICE. 
omo o preconceito se manifesta e como se reproduz? De que códigos ele se vale para disseminar e, por vezes, perpetuar uma condição de submissão e inferioridade absolutamente arbitrária imposta a um grupo étnico ou social por um outro, numérica, política ou economicamente dominante? E como isso ocorre nas histórias em quadrinhos?

As respostas para todas essas questões nunca são fáceis. $\mathrm{O}$ limite entre o meramente jocoso e o francamente ofensivo é extremamente sutil e passível de controvérsias, ainda mais em se tratando do vasto campo das interpretações subjetivas. Uma mesma expressão proferida por uma pessoa em determinada situação ganha significado totalmente inverso quando dita num contexto diferente. À parte a sempre recomendável prática de se analisar um fenômeno social dentro das especificidades de sua realidade histórica, não deixa de ser significativo que uma das justificativas mais recorrentes a flagrantes casos de discriminação racial ou de gênero é a alegação, pelo senso comum, ou seja, a desculpa de que "naquela época era assim mesmo".

Recente episódio envolvendo uma interpretação mais contemporânea do livro Caçadas de Pedrinho colocou sob acusação o seu autor Monteiro Lobato, um dos mais queridos e populares autores brasileiros de literatura infantojuvenil. As passagens que mais incomodaram os críticos foram as menções à baixa intelectualidade da personagem Tia Anastácia, atribuída ao fato de ela ser negra. Durante décadas Caçadas de Pedrinho, publicado originalmente em 1933, foi lido sem que se fizessem ressalvas ao seu conteúdo preconceituoso. Provavelmente, tais detalhes não escapassem aos leitores mais atentos e sensíveis às questões raciais, mas conformados com o espírito de que "naquela época isso era comum", talvez não tenham se sentido à vontade para fazer a denúncia. Outro fator que certamente contribuiu para esse silêncio complacente foi a falta de oportunidades, de meios, e de uma comunidade negra mais articulada e mobilizada que se sentisse forte o suficiente para contestar um autor adotado unanimemente pelas escolas públicas de todo o país.

$\mathrm{Na}$ literatura este é um exemplo recente que teve maior repercussão, mas não são raros os casos de textos carregados de preconceito seja contra negros quanto judeus, asiáticos e outras etnias. Embora tenha sido um caso isolado no universo da literatura é relevante por envolver um autor consagrado, cuja obra vem sendo recomendada a estudantes de pelo menos quatro gerações seguidas. As tramas e personagens de Lobato são bastante conhecidas e já ul- 
trapassaram as fronteiras dos livros e ganharam adaptações em outros meios e linguagens, transformando-se, inclusive, em programas de TV, revista em quadrinhos e outros produtos culturais.

O código linguístico tem, portanto, essa capacidade de transmitir conceitos e preconceitos, servindo a propósitos pouco edificantes, seja de forma intencional ou não. Isso ocorre porque toda palavra traz intrinsecamente uma carga ideológica que não pode ser ignorada. Uma vez que é por meio das palavras que entramos em conexão com o mundo denominando objetos, lugares, sentimentos sensações e pessoas, são elas que nos incutem conceitos positivos e negativos. Naturalmente, também é por meio das palavras que definimos nossa identidade. A nossa em relação aos outros, e a dos outros em relação à nossa.

Identidade e diferença são construções que dependem da linguagem para se definir. A forma como são usados símbolos e palavras inclui ou exclui os indivíduos dentro de determinados conceitos e categorias (SILVA, 2000, p. 93):

... aquilo que dizemos faz parte de uma rede mais ampla de atos linguísticos que, em seu conjunto, contribui para definir ou reforçar a identidade que supostamente apenas estamos descrevendo. Assim por exemplo, quando utilizamos uma palavra racista como "negrão" para nos referir a uma pessoa negra do sexo masculino, não estamos simplesmente fazendo uma descrição sobre a cor de uma pessoa. Estamos na verdade, inserindo-nos em um sistema linguístico mais amplo que contribui para reforçar a negatividade atribuída à identidade "negra".

Desse modo, aquilo que muitas vezes dizemos de forma natural, embute um juízo de valor, estabelece um grau de hierarquia entre grupos e indivíduos.

Nos países de língua inglesa, como em todas as outras sociedades humanas, a maioria das pessoas dispõe de uma gama de termos que estigmatizam outros grupos e que só fazem sentido no contexto de relações específicas entre estabelecidos e outsiders. "Crioulo", "gringo", "carcamano", "sapatão" e "papahóstia" são exemplos. Seu poder de ferir depende da consciência que tenham usuário e o destinatário de que a humilhação almejada por seu emprego tem o aval de um poderoso grupo estabelecido, em relação ao qual o do destinatário é um grupo outsider, com menores fontes de poder (ELIAS, 2000, p. 27). 
Outro autor (GOFFMAN, 1988, p. 11) explica como, com o passar do tempo, os estereótipos passam a ser aceitos por uma coletividade e acabam se tornando estigmas de uma determinada classe ou etnia:

A sociedade estabelece os meios de categorizar as pessoas e o total de atributos considerados como comuns e naturais para os membros de cada uma dessas categorias. Os ambientes sociais estabelecem as categorias de pessoas que têm probabilidade de serem neles encontradas. As rotinas de relação social em ambientes estabelecidos nos permitem um relacionamento com "outras pessoas" previstas sem atenção ou reflexão particular.

Como se pode apreender dessa conceituação, as pessoas ditas "normais" criam uma expectativa em relação a todas as outras pessoas, levando em conta uma série de atributos que as caracterizariam. Em síntese, estabelecem estereótipos que ajudam a construir uma imagem mental de alguém antes mesmo de conhecê-lo. Quando essa imagem, que constitui a identidade social virtual, não corresponde à identidade social real, cria-se o estigma.

Se as palavras podem e, efetivamente, são utilizadas para estabelecer e reforçar diferenças, elas não são as únicas ferramentas disponíveis para tal finalidade. Em se considerando a sabedoria popular, segundo a qual uma imagem vale mais que mil palavras, esta será, portanto, mil vezes mais eficaz e poderosa em disseminar e transmitir estereótipos e preconceitos.

Obviamente, numa forma de expressão que é ao mesmo tempo um meio de comunicação de massa, como o humor gráfico, a intenção é fazer com que o leitor rapidamente identifique o personagem retratado, sem precisar de maiores explicações. Na necessidade de apresentar um negro, um oriental, um judeu, somente por meio de traços, modos e sotaques, a simplificação e a estilização acabam sendo uma exigência da limitação das técnicas de reprodução gráfica. Mas essa generalização, muitas vezes, esbarra no arriscado limite que é tornar-se ofensivo.

O que marca a diferença é o grau de intensidade de ambos os processos: na ausência de outra informação, um certo grau de generalização permite formular previsões; um grau excessivo impede de captar as matizações individuais ou talvez a absoluta falta de correspondência entre o indivíduo real e o que é traçado 
pelo estereótipo; é necessário um mínimo de coerência e estabilidade para que o estereótipo seja útil na interpretação dos outros (MAZZARA, 1999, p. 29).

Na primeira metade do século XIX, os argumentos bíblicos que justificavam a escravidão dos negros foram substituídos por teorias pseudocientíficas (HARRIS, 2003). Ciências como a craniologia, a fisiognomia e a frenologia tentavam achar caracterísitcas físicas que dessem respaldo a uma pretensa hierarquia de raças, obviamente a branca, como sendo superior às demais.

Ainda segundo Harris, Peter Camper, professor de anatomia na Holanda criou um "modelo evolucionista" que demonstrava a diferença entre os humanos baseada na estrutura craniana. Esse modelo, segundo o qual o ângulo formado pela linha do perfil de um rosto era mais vertical quanto mais evoluído o indivíduo, foi amplamente adotado por toda a Europa e influenciou diversos outros trabalhos (Fig. 1).

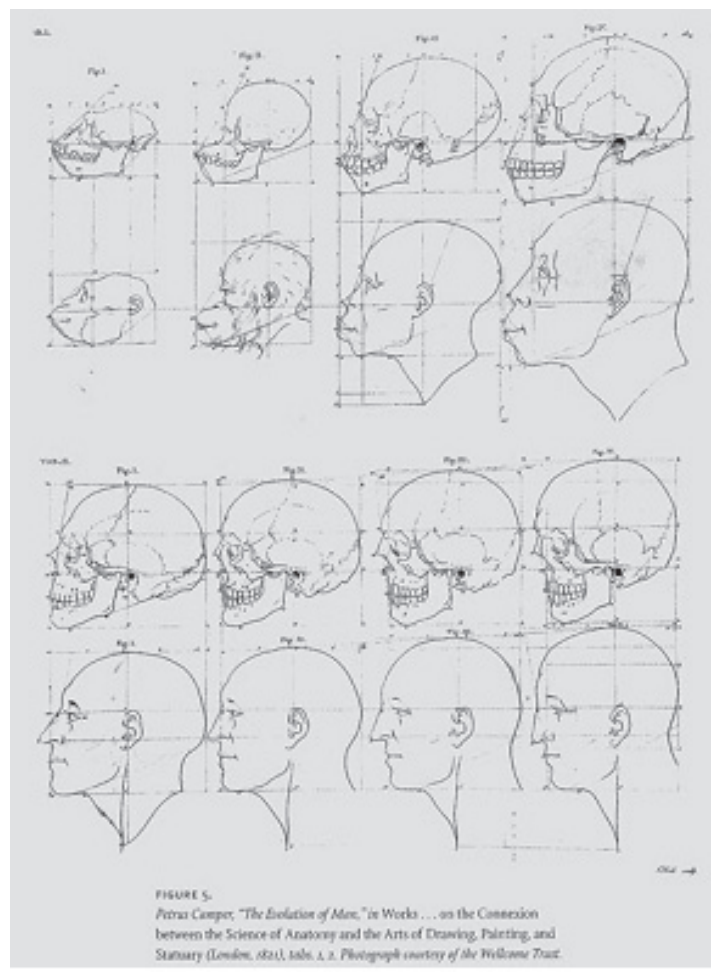

Fig 1. Diagrama de Peter Camper 
Existem diferentes modelos de comicidade. O primeiro deles é o das formas, o visual. Segundo um autor que se debruçou sobre o tema (BERGSON, 2004, p.30) rimos dos negros porque parecem um branco com uma máscara ou o rosto sujo de fuligem:

E por que se ri de um negro? Pergunta difícil, parece, pois psicólogos como Hecker, Kraepelin e Lipps a formularam e responderam de maneiras diferentes. Não sei, porém, se ela não foi respondida certo dia diante de mim, por um simples cocheiro, que tachava de "mal lavado" o cliente negro sentado em sua carruagem. Mal lavado! Um rosto negro seria, portanto, para nossa imaginação, um rosto lambuzado de tinta ou de fuligem. E, consequentemente, um nariz vermelho só pode ser um nariz sobre o qual foi passada uma camada de vermelhão. Portanto, o disfarce passou algo de sua virtude cômica para outros casos em que não há disfarce, mas poderia haver.

É sintomático que Bergson tenha publicado seu trabalho originalmente em 1900, sob a forma de ensaios, mas sua edição em livro tenha ocorrido em 1924, mesma época em que estreou nos cinemas o primeiro filme sonoro da história, "O Cantor de Jazz”, de 1927, em que Al Jolson, um ator branco, pintava o seu rosto de preto para interpretar o papel de um minstrel, figura popular do entretenimento que aliava os talentos de cômico, cantor e dançarino e normalmente era interpretado por um artista branco com a cara pintada.

É interessante notar que longe de ser um inocente instrumento para levar o leitor a momentos de descontração e de diversão sem compromisso, o humor embute um poder de humilhar, de alimentar preconceitos e reforçar animosidades.

Historicamente, o humor sempre foi usado com esse propósito. Desde a antiguidade, os autores costumavam usar da verve humorística para provocar não apenas o riso, mas o escárnio. Expor determinado personagem ou situação ao ridículo foi uma das maneiras mais eficazes de atacá-los.

Freud, inclusive, dedicou especial atenção ao estudo das piadas com o intuito de estudar o prazer provocado pelo riso. Em seu livro Os Chistes e sua Relação com o Inconsciente, ele analisa uma série de anedotas e procura explicar como é construído o efeito cômico em cada um dos exemplos. Na parte em que busca analisar as razões pelas quais esse efeito é obtido (FREUD, 1905, s/p) contextualiza: 
Embora, quando crianças, ainda sejamos dotados de uma poderosa disposição herdada para a hostilidade, logo aprendemos por uma civilização pessoal superior, que o uso de uma linguagem abusiva é indigno; e mesmo onde a luta pela luta permaneceu permissível, aumentou extraordinariamente o número de métodos de luta cujo emprego é vedado. Já que somos obrigados a renunciar à expressão da hostilidade pela ação - refreada pela desapaixonada terceira pessoa em cujo interesse deve-se preservar a segurança pessoal - desenvolvemos, como no caso da agressividade sexual, uma nova técnica de invectiva que objetiva o aliciamento dessa terceira pessoa contra nosso inimigo. Tornando nosso inimigo pequeno, inferior, desprezível ou cômico, conseguimos, por linhas transversas, o prazer de vencê-lo - fato que a terceira pessoa, que não dispendeu nenhum esforço, testemunha por seu riso.

Para Freud, rir do outro é, portanto, a maneira civilizada de agredi-lo, uma vez que a sociedade e seus códigos morais impedem o indivíduo de se manifestar como bem entender. A possibilidade de rir da autoridade, do inimigo, do mais fraco é fonte de prazer que explica o sucesso das sátiras, das caricaturas de políticos e de muitas séries de quadrinhos.

Existem diversos gêneros de quadrinhos: terror, aventura e romance. No entanto, o gênero humorístico é o que mais contribuiu para consolidar essa linguagem mundo afora. Nos Estados Unidos, país que levou a produção dos quadrinhos a padrões industriais, a palavra utilizada para definir os quadrinhos é comics, independente de se tratar de uma narrativa que provoque medo, tensão ou risadas.

\section{O negro no humor gráfico}

A partir desse contexto, é possível fazer um breve painel da representação do negro no humor gráfico brasileiro, de meados do século XIX até boa parte do século XX.

$\mathrm{Na}$ segunda metade do século XIX começaram a surgir nos grandes centros diversas publicações ilustradas, principalmente no Rio de Janeiro, a capital do império. Vários artistas passaram a publicar charges nesses jornais com a intenção de fazer comentários críticos a respeito de temas políticos, econômicos e sociais. 
Com o advento da imprensa ilustrada no Brasil, alguns caricaturistas passaram a publicar charges de cunho político e social. A Guerra do Paraguai foi o primeiro episódio de repercussão nacional a ter a cobertura dessas publicações. O mais destacado artista do humor gráfico dessa época foi Angelo Agostini, considerado o precursor dos quadrinhos brasileiros que desenhou personagens negros em algumas de suas charges, sem usar uma representação do negro que fosse um estereótipo tão exagerado.

Há uma charge clássica que critica a Lei do Ventre Livre em que mostra o soldado negro que volta da Guerra do Paraguai como herói, mas que nesse retorno assiste à sua mãe ser chicoteada no tronco (Fig. 2).

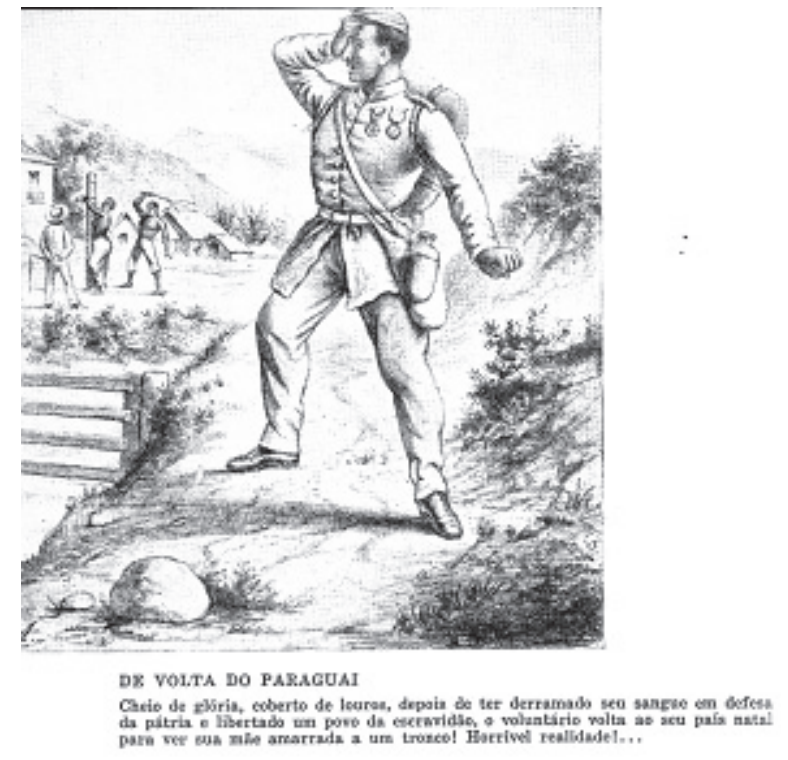

Fig. 2. Charge de autoria de Angelo Agostini

Curiosamente, a imagem com carga mais negativa em relação ao negro eram as feitas pelo inimigo, como demonstra um interessante trabalho sobre a iconografia da Guerra do Paraguai (TORAL, 2001, p. 190), que traz um dos exemplos de como os paraguaios se referiam aos brasileiros como macacos e representava os negros de forma extremamente estereotipada (Fig. 3). 


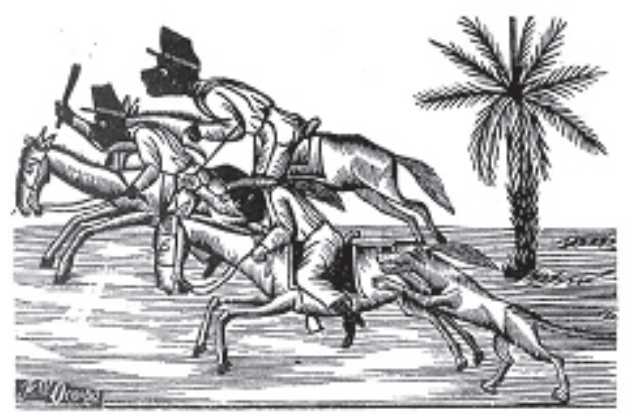

Fig. 3. Charge publicada no jornal paraguaio Cabichuí, em 1868

Com a disseminação das charges, as ilustrações começam a ganhar espaço nas publicações e a linguagem passa por uma evolução que culmina no surgimento de um novo modo narrativo formado por quadros em sequência. Embora esse tipo de arte sequencial tenha sua gênese em formas mais antigas, foi a partir da expansão da imprensa para a grande massa que ela se tornou um fenômeno de comunicação popular, notadamente, nos Estados Unidos e Europa.

Mais tarde, os quadrinhos começaram a ser publicados em vários países e, como não poderia deixar de ser, herdaram das charges muitos dos estereótipos.

No Brasil, esse cenário foi muito parecido. Naquela que os estudiosos consideram como sendo a primeira história em quadrinhos brasileira, já aparece um personagem negro, Benedito, escravo do protagonista Nhô Quim. Criação do já citado Angelo Agostini, a série estreou em 30 de janeiro de 1869, no jornal Vida Fluminense. Em sua homenagem, 30 de janeiro é considerado o Dia do Quadrinho Nacional.

Já o primeiro personagem negro a aparecer com mais regularidade é o Giby, criado em 1907 por J. Carlos, para a revista infantil O Tico-Tico, primeira publicação de quadrinhos do Brasil. Giby era o companheiro do menino Juquinha, que fez grande sucesso e chegou a merecer revista própria. Se a representação de Benedito por Angelo Agostini não era tão caricatural, J. Carlos carregava pesado nos traços de Giby. Lábios exageradamente grossos, orelhas proeminentes na cabeça redonda e lisa são características físicas que irão definir o estereótipo de outros personagens negros que viriam a surgir posteriormente (Fig. 4). 


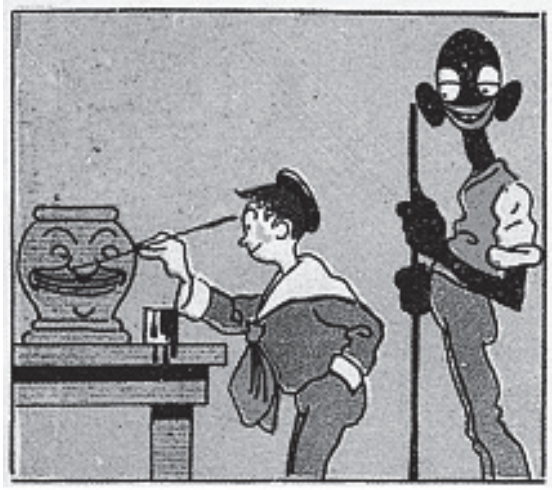

Fig. 4. Juquinha e Giby, de J. Carlos

Na mesma revista O Tico-Tico surgiria, em 1915, mais um personagem negro, Benjamin, que faria muito sucesso como companheiro do garoto Chiquinho, branco e filho do patrão. Baseado na série americana Buster Brown, de Richard Felton Outcault, Chiquinho era literalmente decalcado das páginas originais do personagem por desenhistas brasileiros. No início, Chiquinho contava apenas com a companhia do seu cachorro Jagunço, Tige no original. Com o tempo e o crescente sucesso do personagem, José Loureiro, um dos artistas brasileiros que adaptavam as histórias de Chiquinho, criou o garoto Benjamin para acompanhá-lo em suas travessuras. Nele estão presentes muitas das características físicas exageradas do pioneiro Giby (Fig. 5).
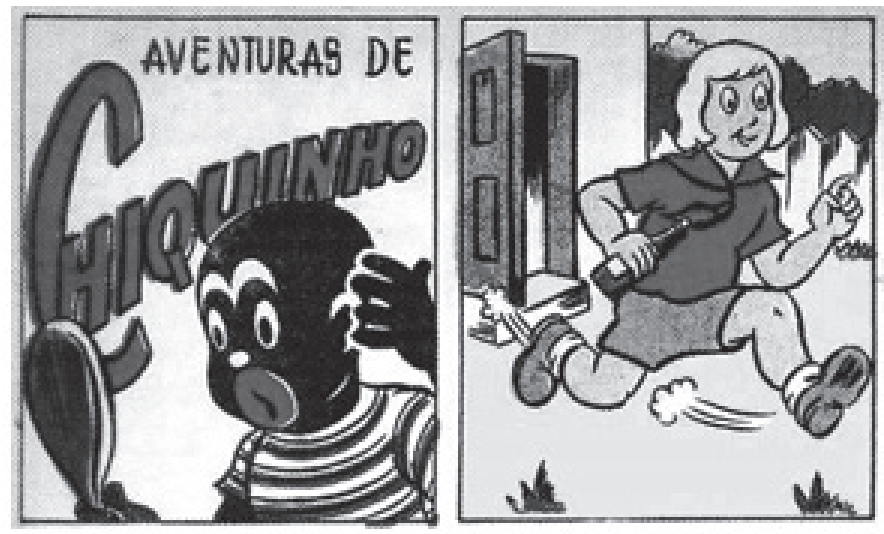

Fig. 5. Benjamim e seu amigo Chiquinho, de José Louzeiro 
Em 1933, e mais uma vez em O Tico-Tico, estreia o trio Reco-Reco, Bolão e Azeitona, do artista Luiz Sá. Os três personagens eram extremamente estilizados, e Azeitona, o negro da turma, não fugia à caracterização usada na época, repetindo o padrão de olhos grandes e lábios grossos. No entanto, seus dois colegas tinham igualmente traços propositadamente exagerados (Fig. 6).

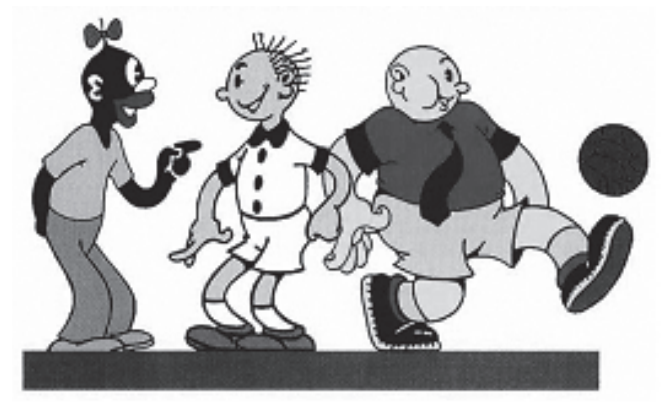

Fig. 6. Azeitona, Reco-Reco e Bolão, de Luiz Sá

J. Carlos, o mesmo artista que havia criado Giby e que viria a se tornar um dos maiores artistas gráficos brasileiros, desenhou um novo personagem para O Tico-Tico: Lamparina, uma representação quase animalesca de uma menina africana com todos os estereótipos mais óbvios, a começar pelo porte físico. Braços exageradamente longos como os de um macaco, modo de andar igualmente simiesco. Para completar, a indumentária era composta por uma tanga de pele de felino sobre o corpo (Fig. 7).

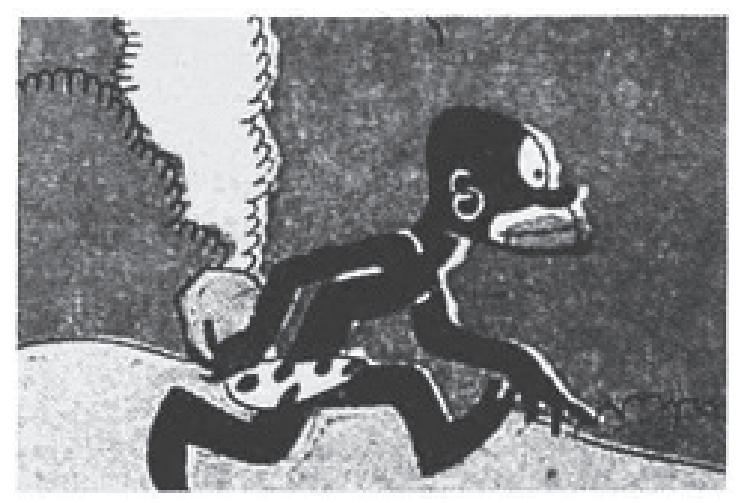

Fig. 7. Lamparina, de J. Carlos 
Em 1935, o chargista Belmonte, autor do famoso personagem Juca Pato, criou para a Gazeta Infantil, os personagens Paulino e Albina. Ele um garoto branco e ela, ironicamente e apesar do nome, uma menina negra (Fig. 8).

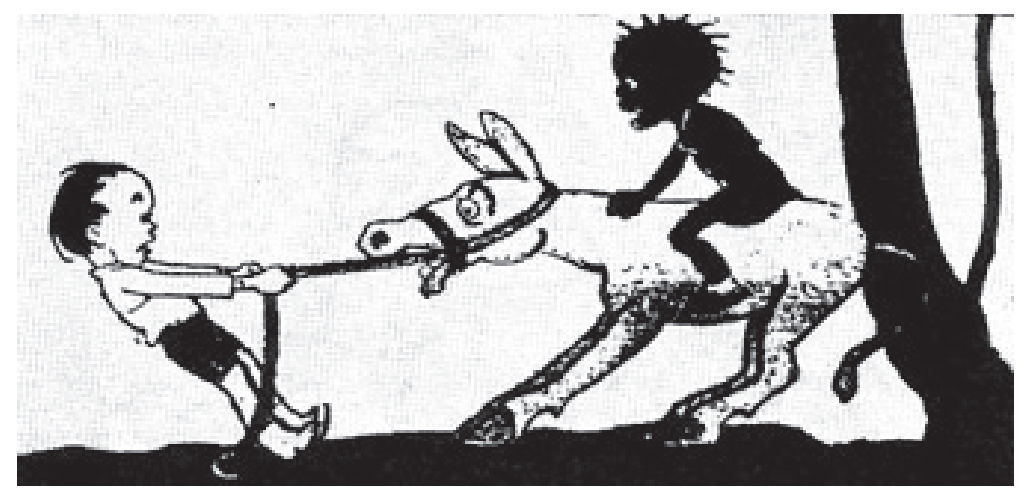

Fig. 8. Paulino e Albina, de Belmonte

Um marco das histórias em quadrinhos no Brasil é o surgimento, em 1939, da revista Gibi, editada pela empresa proprietária do jornal O Globo, de Roberto Marinho. Essa publicação derivada de O Globo Juvenil, rapidamente angariou grande sucesso a ponto circular três vezes por semana e, em 1940, ganhar uma versão mensal, com histórias completas. Nesse formato, ela se tornaria sinônimo de revista em quadrinhos e a palavra "gibi" passou a ser usada como termo genérico para esse tipo de publicação. O curioso é que esse nome deriva da expressão "gibi", etimologicamente significa "moleque negro". Era uma denominação comum a meninos que vendiam jornais nas ruas ou faziam a função de entregar recados. A representação visual do gibi era de um garoto negro com os mesmos traços estereotipados de seus congêneres (lábios exagerados, olhos grandes e esbugalhados, numa face sem nariz), no entanto, embora figurasse com frequência nas capas e mesmo em uma página ou outra da publicação que batizava, o gibi nunca se tornou personagem de quadrinhos. Quando do relançamento da revista Gibi, nos anos 70 , o desenho do mascote foi modernizado, mas manteve os traços carregados de sua versão original (Fig. 9). 


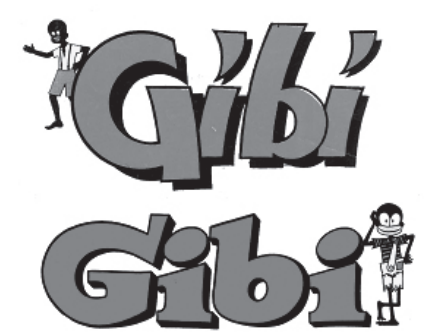

Fig. 9. O Gibi de 1939 e o da década de 1970

Nos quadrinhos americanos, a caracterização do negro foi evoluindo, principalmente depois da década de 1950, quando tiveram início os movimentos pelos direitos civis e as manifestações de combate às leis de segregação ganharam força. No Brasil, ao contrário dos Estados Unidos, o racismo nunca foi algo explícito e declarado. Se lá havia leis que permitiam escolas exclusivas para brancos e proibia os negros de se sentarem na parte da frente dos ônibus, aqui o preconceito era velado e foi necessária uma lei específica (Lei Afonso Arinos) editada em 1951, para criminalizar a discriminação racial. Por isso, havia no país a falsa noção de democracia racial que, de certa maneira, acabou inibindo iniciativas de luta pelos direitos dos negros.

Isso se refletiu no humor gráfico que, mesmo em tempos mais recentes, continuou abusando de estereótipos para fazer graça.

Jeremias, único personagem negro da Turma da Mônica, de Mauricio de Sousa, foi criado em 1960 e figurou na capa da primeira revista do Bidu. Comparando os primeiros desenhos e os mais recentes, é possível notar que houve uma atualização nos traços, e, no caso de Jeremias, a mudança é notável (Fig. 10).
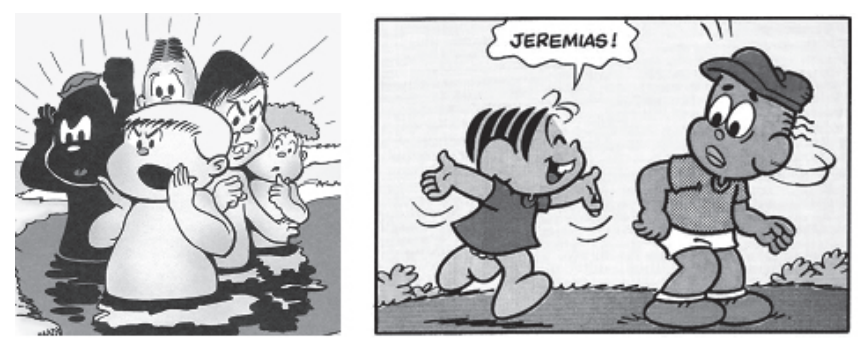

Fig. 10. Jeremias, de Mauricio de Sousa, o antigo e o atual 
$\mathrm{Na}$ transposição dos personagens de Os Trapalhões da tevê para os quadrinhos ocorre um fenômeno interessante. Nos idos das décadas de 1970/80, os programas televisivos de humor exploravam descaradamente o preconceito. Muitos dos sketches do grupo baseavam-se na figura do nordestino Didi, interpretado por Renato Aragão, e do negro Mussum, com piadas explicitamente baseadas em clichês. O sucesso do programa fez com que fosse adaptado para os quadrinhos publicados em revistas próprias editadas pela Bloch. O estilo de humor foi mantido nos roteiros das histórias em quadrinhos, mas no decorrer da publicação houve uma mudança drástica na caracterização visual do quarteto do qual faziam parte, além de Didi e Mussum, seus colegas Dedé e Zacarias. A princípio, os personagens eram caricaturas com um nível mínimo de realismo, de modo a lembrar os atores reais. Como as histórias eram produzidas por diferentes artistas, há episódios em que os personagens são desenhados de forma totalmente estilizada e Mussum ganha traços extremamente simplificados, que se restringiam a olhos grandes e lábios grossos, como os que caracterizavam os primeiros negros dos quadrinhos (Fig. 11).
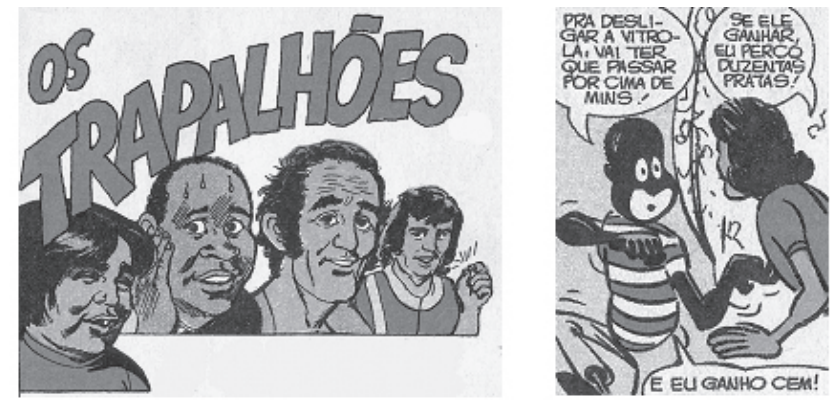

Fig. 11. O personagem Mussum em duas versões

Em termos de representação gráfica isso representou um retrocesso.

A mesma regressão, desta vez intencional, pode ser verificada na revista Bundha, lançada em 1987, com o mesmo nome do personagem principal, um negro africano caracterizado de forma primitiva, como um selvagem, inclusive no seu linguajar e modo de se expressar. A intenção do autor, Newton Foot, era explorar ao máximo as discutíveis utilizações humorísticas do trocadilho com o nome do protagonista. A maioria das situações cômicas era baseada num malicioso jogo de palavras, muitas vezes infame. Para completar, 
o companheiro de Bundha era outro negro: Tanga, também caracterizado de forma estereotipada, mas como um malandro urbano, com direito a chapéu. Com Tanga, ampliaram-se as possibilidades de trocadilho, mas, aparentemente, o repertório logo se esgotou, pois a revista teve curta duração (Fig. 12).
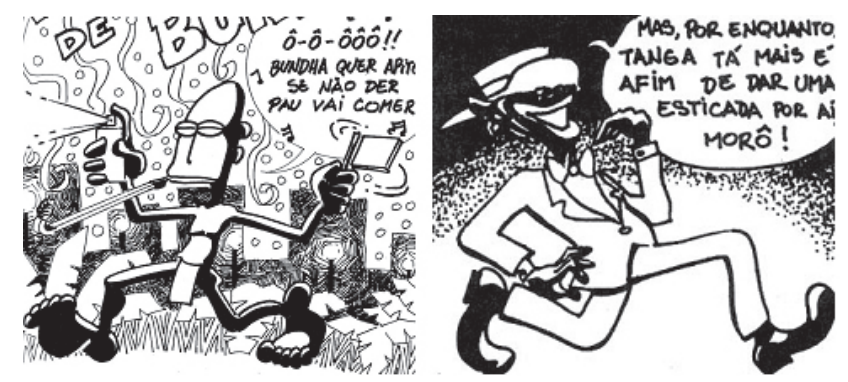

Fig. 12. Bundha e seu amigo Tanga, de Newton Foot

Mesmo autores mais engajados com a crítica social e que denunciavam o preconceito disfarçado dos brasileiros usavam de traços exagerados para representar os negros. Henfil, um dos mais prolíficos e politicamente ativos chargistas do Brasil e que atuou em plena época da ditadura militar, ao criar personagens negros exagerava nos traços e caracterizações.

Mais uma vez volta à tona a complexa questão do limite entre o preconceito e a representação estilizada para fins de tornar a caracterização mais imediata ao leitor. A carga negativa que poderia se atribuir aos quadrinhos de Henfil é obviamente anulada pelo conteúdo e a narrativa. Não há a intenção de ofender os negros, pelo contrário, a mensagem é de condenação ao preconceito.

$\mathrm{O}$ mesmo pode ser deduzido de iniciativas recentes como a da história $O$ Quilombo Orum Aiê, de André Diniz. Publicada em álbum pela Editora Galera, em 2010, é uma narrativa épica, ambientada nos tempos da escravidão e fala de um grupo de negros fugidos em busca de um local místico, uma espécie de Eldorado, onde poderiam viver em paz e liberdade. A temática é centrada na luta dos negros pela liberdade e faz uso de referências da cultura negra. O artista optou por adotar um estilo semelhante ao da xilogravura, sem meios tons e predomínio de traços simples e estilizados, que lembrasse as decorações rituais dos negros africanos. Essa solução, no entanto, acabou aproximando a caracterização das personagens do estereótipo de outras épocas (Fig. 13). 


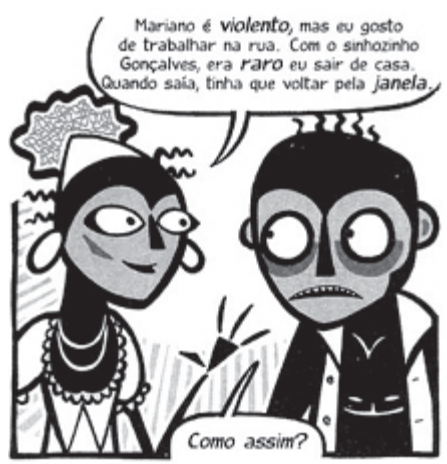

Fig. 13. Sinhana e Capivara, de O Quilombo Orum Aiê, de André Diniz

Os exemplos citados no presente artigo demonstram como durante décadas a representação do negro nos quadrinhos seguiu um padrão estereotipado e preconceituoso, fruto de uma sociedade que se dizia imune ao racismo.

É preciso deixar claro que intencionalmente foram selecionados os mais significativos dentro do que se propunha a debater. Trabalhos mais recentes procuram não incorrer nos mesmos erros do passado e evitam o tom ofensivo e desrespeitoso. Isso não significa que devamos misturar as coisas, pois Henfil e Diniz são exemplos que valorizam o elemento negro e a sua cultura. Um pouco de exagero talvez seja a medida correta para derrubar a sisudez e a falta de bom humor que reina no politicamente correto.

\section{O negro pelo negro}

Se a representação do negro nos quadrinhos sofreu um processo evolutivo, também é interessante questionar como isso ocorreu sob o ponto de vista do próprio negro não como personagem, mas como autor, analisando-se a obra de artistas afrodescendentes que produziram quadrinhos. Nenhum dos personagens citados neste artigo foi criado por autores negros, o que em parte ajuda a compreender, mas não justificar, esse histórico de estereótipos e, nos quase 100 anos de humor gráfico analisados, não há registro de quadrinhos com temática relativa aos afrodescendentes ou à sua cultura cujo autor seja também negro. Certamente, pode ter existido algum caso que atenda a esses 
requisitos, mas se houve não teve repercussão suficiente para constar da bibliografia sobre o assunto. A exceção mais notável é uma biografia de Zumbi em quadrinhos, roteirizada pelo sociólogo Clóvis Moura e ilustrada por Álvaro de Moya, na década de 1950. Somente em anos mais recentes, autores negros se dedicaram a transpor para os quadrinhos as situações de desigualdade e de preconceito em relação aos negros. O pioneiro autor a seguir essa vertente foi o professor de sociologia Bonifácio Rodrigues de Mattos, mais conhecido pelo pseudônimo de Ykenga, e que, desde a década de 70, publicava suas charges na revista Ébano. Como militante do movimento negro, colaborou com vários jornais de comunidades do Rio de Janeiro e no alternativo Pasquim, mas também publicou na grande imprensa como os jornais $O$ Globo e Jornal do Brasil. Sua série mais conhecida é Casa Grande Sem Sala, em cujas tiras são retratados os contrastes sociais e, principalmente, as mazelas sofridas pelas camadas menos privilegiadas, simbolicamente representadas por vários personagens, entre os quais o negro Joãozinho Tresoitão.

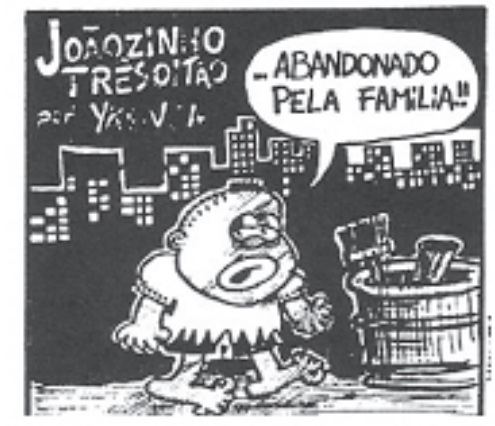

Fig. 14. Personagem da série Casa Grande Sem Sala, de Ykenga

Outro autor que tem a carreira marcada por uma forte militância pela igualdade de direito dos negros é Mauricio Pestana. Praticamente toda a sua obra é dedicada a denunciar a discriminação e a desigualdade de que a população negra historicamente foi vítima, muitas vezes de forma intransigente, manifestada em álbuns como o Violência histórica. Pestana também vem produzindo quadrinizações de episódios da história do Brasil, como a Revolta dos Búzios e a Revolução Paulista de 1932, em que o papel dos negros foi determinante, fato que os livros oficiais jamais fizeram questão de abordar. 


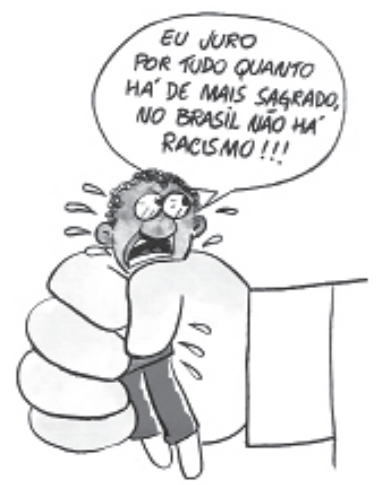

Fig. 15. Cartum antirracista de Mauricio Pestana

Um terceiro autor negro que também trata da realidade contemporânea dos afrodescendentes é Marcelo D'Salete. No entanto, diferentemente de Ykenga e Pestana, seu trabalho não possui um engajamento explícito, sua obra tem características mais sutis e melancólicas, mas não menos graves. As histórias de Marcelo contemplam o cotidiano de gente simples da periferia, seus problemas de convivência com a criminalidade interferindo em suas vidas e a falta de perspectiva de um ambiente em que o mais fraco é humilhado pelo mais violento.

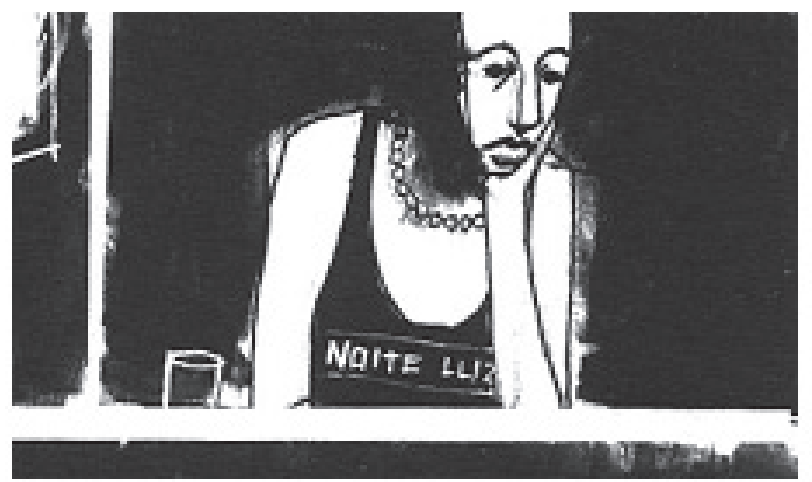

Fig. 16. Personagem do álbum Noite Luz, de Marcelo D’Salete 


\section{Referências bibliográficas}

BERGSON, Henri. O riso. Ensaio sobre a significação da comicidade. São Paulo: Martins Fontes, 2001.

CARDOSO, Athos Eichler. Memórias d'O Tico-Tico. Juquinha, Giby e Miss Shocking. Quadrinhos Brasileiros 1884-1950. Brasília, Senado Federal, 2009.

CIRNE, Moacy. História e crítica dos quadrinhos brasileiros. Rio de Janeiro: Funarte/ Europa, 1990.

ELIAS, Norbert; SOOTSON, John L. Os estabelecidos e os outsiders. Rio de Janeiro: Jorge Zahar, 2000.

FREUD, Sigmund. Os chistes e sua relação com o inconsciente. Edição eletrônica das obras psicológicas completas. Vol. VIII. Rio de Janeiro: Imago, 1997.

GOIDA (Hiron Cardoso Goidanich). Enciclopédia dos quadrinhos. Porto Alegre: L\&PM Editores, 1990.

GOFFMAN, Erving. Estigma: notas sobre a manipulação da identidade deteriorada. $4^{\mathrm{a}}$ ed. Rio de Janeiro: LTC, 1988.

HARRIS, Michael D. Colored pictures. Race \& visual representation. Chapel Hill: The University of North Carolina Press, 2003.

MAZZARA, Bruno M. Estereótipos y prejuicios. Madrid: Acento Editorial, 1999.

MOYA, Álvaro de. História da História em quadrinhos. $2^{\text {a }}$ ed. São Paulo, Brasiliense, 1996.

SILVA, Tomaz Tadeu da. A produção social da identidade e da diferença. In: SILVA, Tomaz Tadeu da (org.). Identidade e diferença. Petrópolis: Vozes, 2000.

TORAL, André. Imagens em desordem. São Paulo: Humanitas/FFLCH/USP, 2001.

Recebido em 20 de agosto e aprovado em 15 de setembro de 2010. 